\title{
Cesarean section in the People's Republic of China: current perspectives
}

This article was published in the following Dove Press journal:

International Journal of Women's Health

9 January 2014

Number of times this article has been viewed

\author{
Xing Lin Feng' \\ Ying Wang' \\ Lin $\mathrm{An}^{2}$ \\ Carine Ronsmans ${ }^{3}$ \\ 'Department of Health Policy \\ and Administration, School of \\ Public Health, Peking University, \\ Beijing, People's Republic of China; \\ 2Department of Women, Children \\ and Adolescent Health, School of \\ Public Health, Peking University, \\ Beijing, People's Republic of China; \\ ${ }^{3}$ Department of Infectious Disease \\ Epidemiology, London School of \\ Hygiene and Tropical Medicine, \\ London, England
}

Objective: To review the current knowledge on the prevalence, reasons, and consequences of cesarean sections in the People's Republic of China.

Methods: Peer-reviewed articles were systematically searched on PubMed. The following Chinese databases were comprehensively searched: the China National Knowledge Infrastructure, Wanfang, and the VIP information. The databases were searched from inception to September 1, 2013. Two reviewers independently screened the titles and abstracts for eligibility. Full texts of eligible papers were reviewed, where relevant references were hand-searched and reviewed.

Findings: Sixty articles were included from PubMed, 17 articles were intentionally picked out from Chinese journals, and five additional articles were added, for a total of 82 articles for the analysis. With a current national rate near $40 \%$, the literature consistently reported a rapid rise of cesarean sections in the People's Republic of China in the past decades, irrespective of where people lived or their socioeconomic standing. Nonclinical factors were considered as the main drivers fueling the rise of cesareans in the People's Republic of China. There was a lively debate on whether women's preferences or providers' distorted financial incentives affected the rise in cesarean sections. However, recent evidence suggests that it might be the People's Republic of China's health development approach - focusing on specialized care and marginalizing primary care - that is playing a role. Although 30 articles were identified studying the consequences of cesareans, the methodologies are in general weak and the themes are out of focus.

Conclusion: The overuse of cesareans is rising alarmingly in the People's Republic of China and has become a real public health problem. No consensus has been made on the leverage factors that drive the cesarean epidemic, particularly for those nonclinical factors. The more macro level structural factors may have played a part, though further research is warranted to understand the mechanisms. Knowledge of the consequences of cesareans, particularly for women, is limited in the People's Republic of China, leaving a substantial literature gap.

Keywords: cesarean section, People's Republic of China

\section{Introduction}

Cesarean sections have been a global public health concern for decades. ${ }^{1-3}$ As a key component of comprehensive emergency obstetric care (EmOC), the adequate provision of cesarean sections during intrapartum care is a life-saving procedure., ${ }^{2,3}$ This is particularly vital for mothers living in low and middle income countries, where access to EmOC is low and resources to provide quality care are limited. ${ }^{3-5}$ Notwithstanding the well-recognized life-saving role of cesarean sections, international comparisons show that rates of cesarean sections vary greatly across countries and high coverage does not necessarily lead to good health outcomes. ${ }^{1,2}$ Elective cesareans can increase the risk of maternal morbidity, neonatal death, and neonatal admission to an
Correspondence: Xing Lin Feng

Department of Health Policy and Administration, School of Public Health, Peking University, 38 Xueyuan Rd, Beijing, People's Republic of China 100191

Tel +86 1082805394

Emailfxl@bjmu.edu.cn 
intensive care unit. ${ }^{1}$ The overuse of cesareans is therefore a real public health concern, not only because cesareans are costly, incurring a financial burden for the families and society, but also because they may entail a health risk for women and children's health. The threshold above which cesarean sections are in excess of need is not well known, but the World Health Organization suggests a maximum threshold of around $15 \%{ }^{6}$

Recent global estimates consistently show that rates of cesareans have been rising dramatically over the recommended threshold, particularly in Latin American and some Asian countries. ${ }^{7,8}$ The debate on why rates of cesareans rise quickly continues, and both supply and demand side factors are thought to play a role. ${ }^{1,9}$ The preponderance of obstetricians in providing intrapartum care and the perverse financial incentives associated with cesareans are the main factors considered from the supply side, whilst for the demand side, discussions center around women and families' preferences. To date no consensus has been reached on the main factors driving the cesarean epidemic.

As the largest developing country, the People's Republic of China bears a substantial burden of maternal and child mortality worldwide, and was included as one of the 68 countdown countries to achieve the two Millennium Development Goals (MDG) related to maternal and child health (MDG 4 and 5). ${ }^{10,11}$ To address the high burden of maternal mortality, a universal hospital delivery strategy was introduced by the Chinese government in the mid-1990s. ${ }^{12}$ In 1995, the Law on Maternal and Infant Health Care was passed to guarantee each woman's right to a hospital for quality intrapartum care. Both supply and demand side interventions have been put forward since then. Infrastructure has been strengthened, medical staff were trained and supervised in township and lower level hospitals, and referral channels to tertiary hospitals were reinforced. ${ }^{12}$ In 2003, the government launched the New Cooperative Medical Scheme (NCMS), which provides health insurance coverage for the majority of the rural Chinese population for medical care, including hospital delivery. By 2007, health insurance had achieved near universal coverage in the People's Republic of China, greatly increasing the financial accessibility to facility-based intrapartum care for the Chinese population. ${ }^{13}$

Consistent national data show that the People's Republic of China's hospital delivery strategy has been successful in reducing maternal and neonatal mortality. ${ }^{10,11}$ In 1988, less than half of all women gave birth in a hospital, yet 20 years later hospital births have become nearly universal and socioeconomic inequalities in hospital births have nearly disappeared. ${ }^{13}$ Over the same period, maternal mortality declined by $47 \%-86 \%$ and neonatal mortality by $48 \%-70 \%$. As a result, the People's Republic of China is now quoted as a successful example in the developing world in achieving MDG 4 and 5. ${ }^{10,11}$ At the same time however, rates of cesarean sections have been rising dramatically. In 2007-2008, the national rate was $46.2 \%$ and $40 \%$ of cesareans were reported to have no clinical indications. ${ }^{14}$

In this paper, we systematically reviewed peer-reviewed articles in both Chinese and international journals on the theme of cesarean sections in the People's Republic of China. From a multidisciplinary perspective, particularly health policy and systems research, we discuss the current knowledge on the prevalence, reasons, and consequences regarding cesarean sections in the People's Republic of China. We add up the literature not only by describing the specific phenomenon from the People's Republic of China, but also by contributing to the international debate on why cesareans rise and how it might be related to a country's health system development.

\section{Search strategy and findings}

We systematically searched PubMed for peer-reviewed articles. Since only a limited amount of Chinese journals were indexed by PubMed, we also comprehensively searched the following Chinese databases: the China National Knowledge Infrastructure, Wanfang, and the VIP information. The databases were searched from inception to September 1, 2013. To identify further relevant studies, reference lists of included articles were hand-searched and reviewed.

When searching PubMed, we included studies that reported "caesarean" OR "cesarean" OR "caesarean section" OR "cesarean section" with "China" OR "Chinese" in the title. We restricted the study subjects to humans. The following study types were included: clinical trial, meta-analysis, randomized controlled trials, and all types of observational studies, including cohort studies, case control studies, crosssectional studies, and case reports.

The searching of Chinese databases resulted in more than 20,000 papers. However, since most of the Chinese journals, which are not indexed by PubMed, are not peer-reviewed and the majority of these papers are not original research, we screened the title and abstract and intentionally chose important and relevant articles for this review.

Finally, we got 97 results on PubMed. Two reviewers independently screened the search results by title and abstract for potential eligibility. Thirty-seven articles were excluded for irrelevancy and 60 articles were included. 
Full texts of these potentially suitable articles were obtained and reviewed. With 17 articles picked out from Chinese databases and five additional papers hand-searched, we finally arrived at 82 papers for this analysis (Figure 1). Amongst these articles, 30 reported the prevalence and trends in cesareans, 48 reported the reasons for performing cesareans, and 30 reported the consequences of cesareans, where 23 articles reported both the prevalence and the reasons, 1 reported both the prevalence and the consequences, and one reported all three themes.

The following search formula was used for PubMed: ("humans"[MeSH Terms] AND (Clinical Trial[All Fields] OR Meta-Analysis[All Fields] OR Randomized Controlled Trial[All Fields] OR Case Reports[All Fields] OR Classical Article[All Fields] OR Clinical Trial, Phase I[All Fields] OR Clinical Trial, Phase II[All Fields] OR Clinical Trial, Phase III[All Fields] OR Clinical Trial, Phase IV[All Fields] OR Comparative Study[All Fields] OR Controlled Clinical Trial[All Fields] OR Corrected and Republished Article[All Fields] OR English Abstract[All Fields] OR Evaluation Studies[All Fields] OR Historical Article[All Fields] OR Journal Article[All Fields] OR Multicenter Study[All Fields] OR Twin Study[All Fields])) AND (caesarean OR caesarean section OR cesarean OR cesarean section) AND
(China [title] OR Chinese [title]) AND (China [All Fields] NOT "veterinary"[MeSH Subheading]).

\section{Prevalence and trends in cesareans}

There are two major types of studies estimating the prevalence of and trends in cesarean sections in the People's Republic of China: hospital-based studies and population surveys (Table 1).

\section{Hospital-based studies}

The earliest attempts used hospital records to report trends in cesarean sections in specific hospitals, categorizing cesareans by clinical indications. A typical example was Zheng et al. ${ }^{15}$ Using clinical records from one of the best tertiary hospitals in Beijing, they reported that the proportion of cesarean births was low in 1960 (2.0\%), increasing dramatically to $50.0 \%$ in 1994. The authors categorized clinical decisions into five groups: 1) maternal factors, including pregnancy-induced hypertension and medical complications during pregnancy; 2) fetal factors, including fetal distress and placental position abnormality; 3) cephalopelvic disproportion; 4) social factors; and 5) other factors. Interestingly, a category of "social factors" was included, increasing from $0 \%$ of cesareans in 1960 to $10.7 \%$ in 1994 .

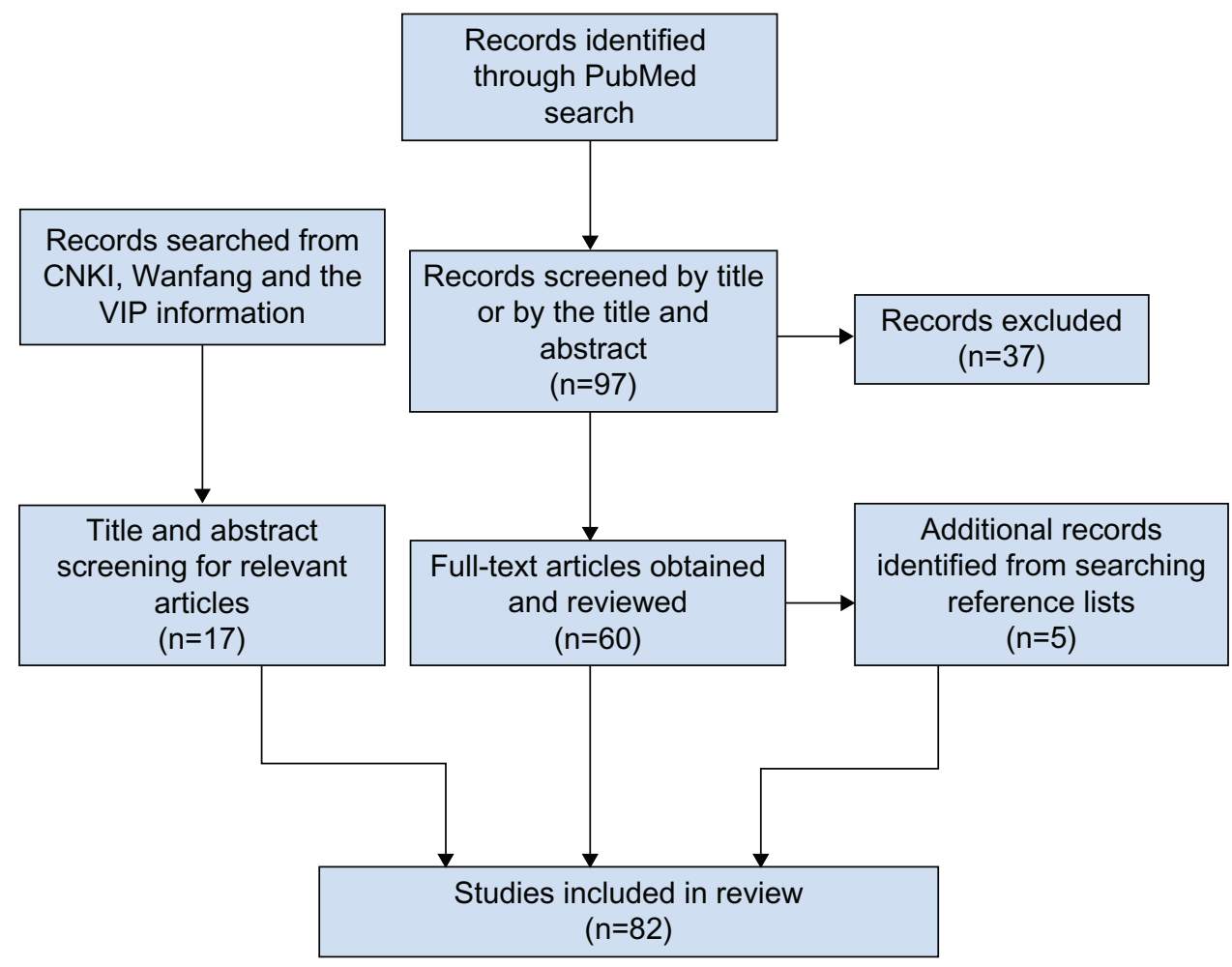

Figure I Flowchart demonstrating literature review procedure. Abbrevation: CNKI, China National Knowledge Infrastructure. 


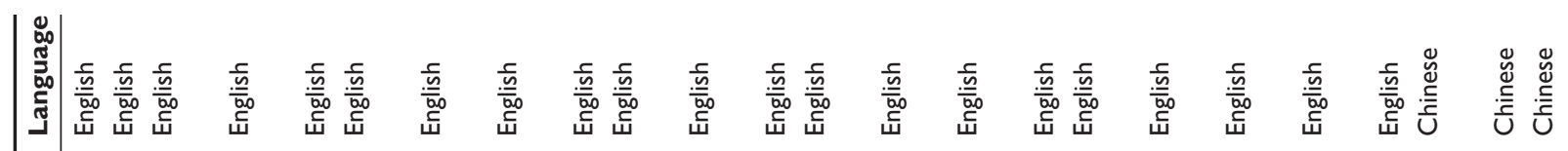

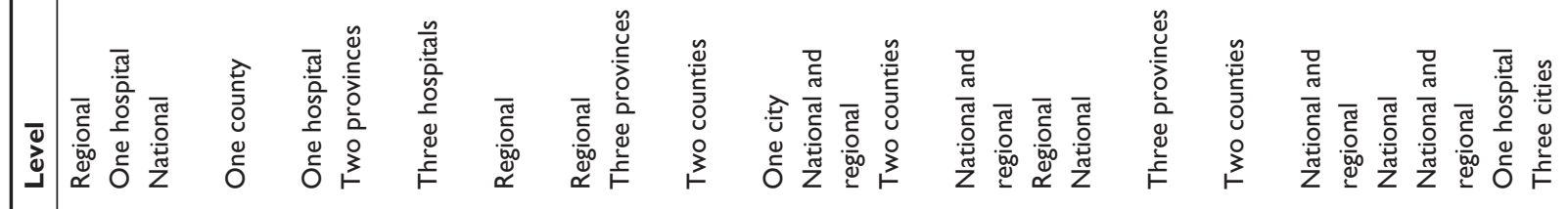

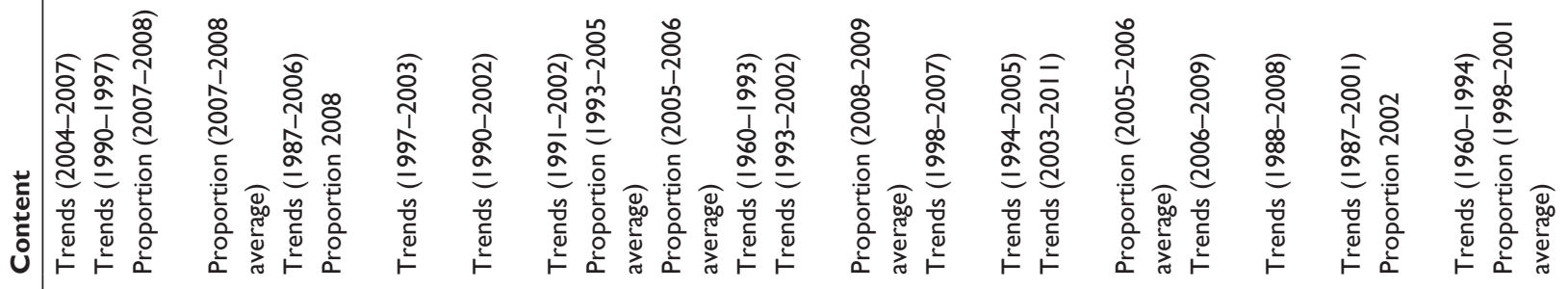

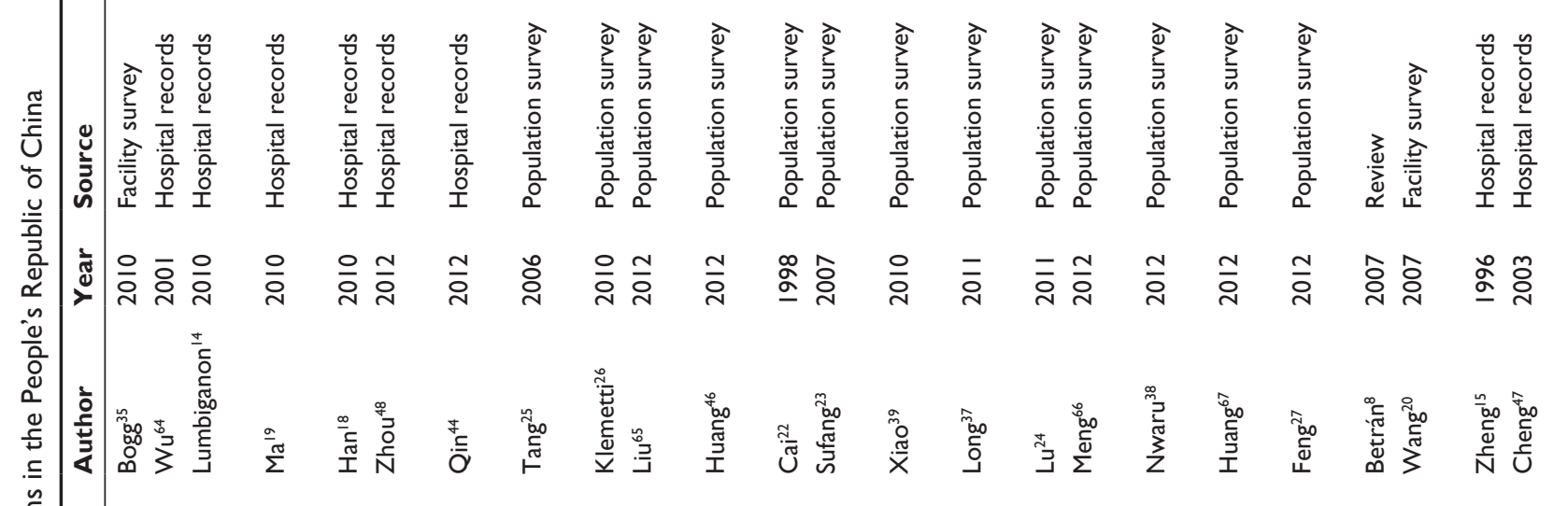




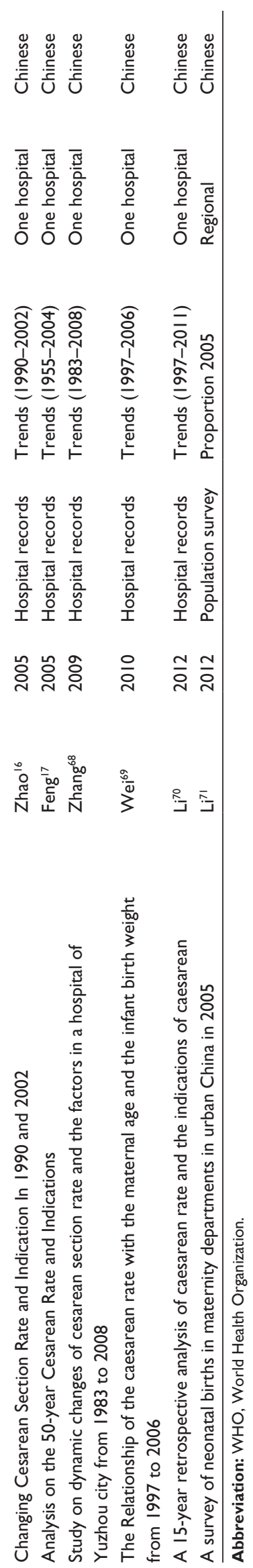

Eleven similar analyses followed such a paradigm. For example, Zhao et al ${ }^{16}$ reported that cesareans increased from $25.4 \%$ of births in 1990 to $39.6 \%$ in 2002 in a secondary level hospital, and Feng and Yue ${ }^{17}$ reported a rise from $2.6 \%$ in 1955 to $64.7 \%$ in 2004 in a tertiary hospital in middle China. Such types of studies also appeared in English peer-reviewed journals, for example Han et al ${ }^{18}$ and Ma et al. ${ }^{19}$ In summary, these analyses consistently reported a substantial rise in the proportion of social factors, which has become the leading reason affecting clinical decisions to perform cesarean sections in recent years.

In the second type of studies - health facility surveys information is also based on hospital records; each hospital itself was required to calculate the proportion of cesarean deliveries. There were very few studies in this category (only three). For example, Wang et $\mathrm{al}^{20}$ surveyed 887 health facilities for six types of birth attendance procedures taken in the year 2002. They reported a national rate of cesarean section at $38.0 \%$ and extremely low utilization of sericeps and forceps in birth attendance. While the strength of this type of research is that it could yield robust national rates, the weakness is that trends could not be arrived at due to the hardship in organizing facility surveys from academic institutions.

The above two study designs based on hospital records could yield robust estimates of trends and proportions of cesarean section for births in hospitals. However, as illustrated by a systematic review based on other countries, ${ }^{21}$ information extracted from clinical records may yield nontrivial misclassifications for clinical indications on the categorization of cesarean sections. Furthermore, such types of studies ignore births that are out of health facilities, resulting in an overestimate of the rates of cesarean section at national or regional level. Hospital records also lack information on the socioeconomic characteristics of the population level, limiting the scope for further policy analysis.

\section{Population-based surveys}

In 1998, Cai et al ${ }^{22}$ conducted a population-based survey in a district in Shanghai, one of the largest metropolitan cities in the People's Republic of China. Using information on cesarean sections collected from women's recall, the authors reported, for the first time, a rise of cesarean sections from $4.7 \%$ from $1960-1979$ to $22.5 \%$ from $1988-1993$ at the population level. Cai et al also analyzed whether cesarean sections were associated with clinical, demographic, and socioeconomic factors. They found that medical insurance coverage, older maternal age, high birth weight, and self-reported complications were factors affecting the 
utilization of cesareans. Following Cai et al, population-based surveys became the design of choice to estimate rates of cesarean section and their determinants (15 studies as shown in Table 2). For example, Sufang et $\mathrm{al}^{23}$ reported trends in cesareans in the People's Republic of China between 1993 and 2002 using a national cross-sectional survey and Lu et $\mathrm{al}^{24}$ reported trends in southern China between 1994 and 2005.

Repeated cross-sectional surveys were also used for the estimation of longer time trends. Using the People's Republic of China's National Health Service Surveys, Tang et $\mathrm{al}^{25}$ reported trends in cesareans in urban China from 1990-2002, while Klemetti et $\mathrm{al}^{26}$ reported such trends in rural China from 1991-2002. With the same national data, Feng et $\mathrm{al}^{27}$ did a comprehensive analysis on the trends in cesarean section rates in the People's Republic of China from 1988 to 2008. Using the four national surveys conducted in the years 1993, 1998, 2003, and 2008, the study estimated the People's Republic of China's national cesarean section rates at 3.4\% in 1988 , increasing ten-fold to $39.3 \%$ in 2008 . The most extraordinary increase was witnessed in urban settings, where $64.1 \%$ of the women gave birth by cesarean section in 2008; while even in the least developed rural region, the rate rose from $0 \%$ in 1988 to $11.3 \%$ in 2008 .

\section{Reasons for performing cesarean sections}

Both clinical factors and nonclinical factors were investigated to explain the epidemic of cesarean sections in the People's Republic of China. While studies on clinical factors for choosing cesareans are relatively rare and disagreement is seldom made, the debates on nonclinical factors are quite lively and in-depth, particularly on whether the rise in cesareans in the People's Republic of China are fueled by the women's own choice or the obstetricians' induced demand. A comprehensive list of studies addressing the factors that affect the use of cesarean sections in the People's Republic of China is shown in Table 2. In summary, there are 14 studies focusing on clinical factors and 34 studies on nonclinical factors.

\section{Nonclinical factors}

As early as 1989, following an observation that rising cesareans were not associated with a reduction in perinatal mortality, a national academic conference was organized in the obstetricians' society to discuss clinical indications for cesarean sections. ${ }^{28}$ Among the clinical indications, "precious child" was increasingly reported, alongside other more conventional clinical factors. There was no clear definition of what was meant by "precious child," and the terminology evolved to a broader but equally undefined category of "social factors." ${ }^{15,17}$ Clinical records from various hospitals in the People's Republic of China consistently show a rise in the proportion of cesareans performed for "social factors" and "social factors" have recently become the leading reason in some hospitals. ${ }^{15-17}$

\section{Women's preferences}

There are 11 studies that reported on the women's choice for performing cesarean sections. From in-depth interviews based on relatively small sizes, qualitative evidence shows that cesareans may in part be due to women's own choices; where convenience, perceived safety, painless birth, and choice of birth date are the main reasons for cesarean preferences. Some women even believe that a baby delivered by cesarean section may be cleverer because the baby was not squeezed in the birth canal. ${ }^{29-31}$

Over time, various authors have introduced a new terminology in their analyses: a cesarean delivery on maternal request (CDMR). For example, Zhang et al proposed a number of criteria to define CDMR. ${ }^{32}$ The five criteria that are required to qualify as CDMR are: singleton birth, cesarean delivery based on "woman's request," the fetus is alive prior to delivery, gestational age of 38 weeks or more, and cesarean section before onset of spontaneous or induced labor. The following eight criteria disqualify women from CDMR: previous cesarean delivery, malpresentation, placenta previa, antepartum placenta abruption, antepartum severe preeclampsia, abnormal fetal heart rate before labor, suspected fetal growth restriction, and suspected large-forgestational-age fetus. Using this definition, the authors found that while cesarean section rates rose from 22\% in 1994 to $60 \%$ in 2003 in Southeast China, the proportion that was accounted for by CDMR rose from less than $1 / 20$ to more than $1 / 3$ over the decade.

Since good quality clinical information is required to define a CDMR, it cannot be identified through population surveys. Long et $\mathrm{al}^{33}$ proposed a simple definition of nonemergency cesareans to be used in survey instruments. Emergency cesareans were identified by asking the woman whether she felt that her child's or her own condition were in danger such that a cesarean was necessary. With population survey data from five rural counties, the authors found that half of the nonemergency cesareans were suggested by a doctor and half by the women's own choices.

None of the above classifications are free of substantial misclassifications. First, since obstetricians are powerful in clinical decisions, the power imbalance between providers and 


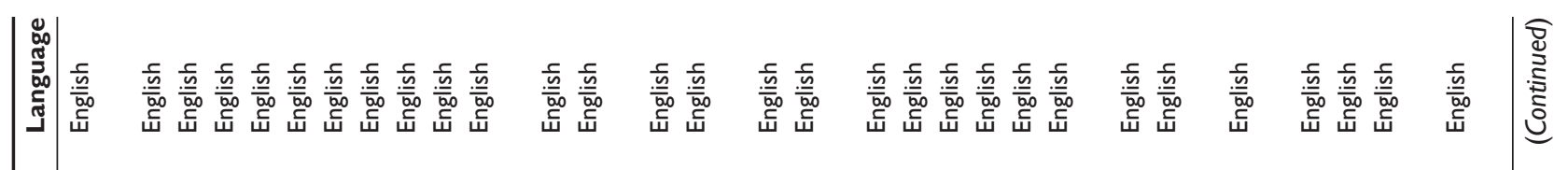

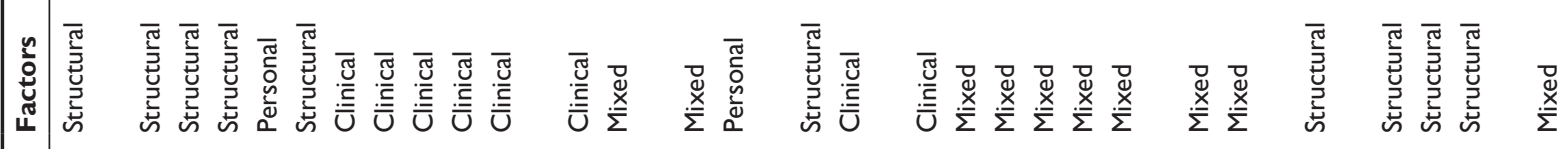

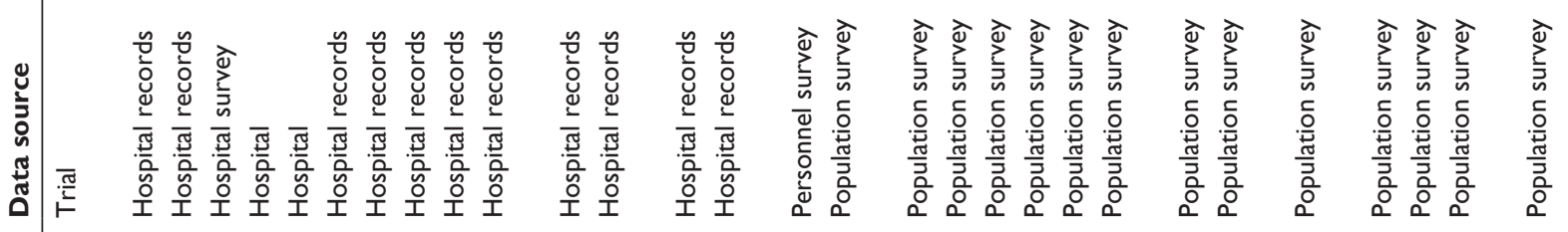

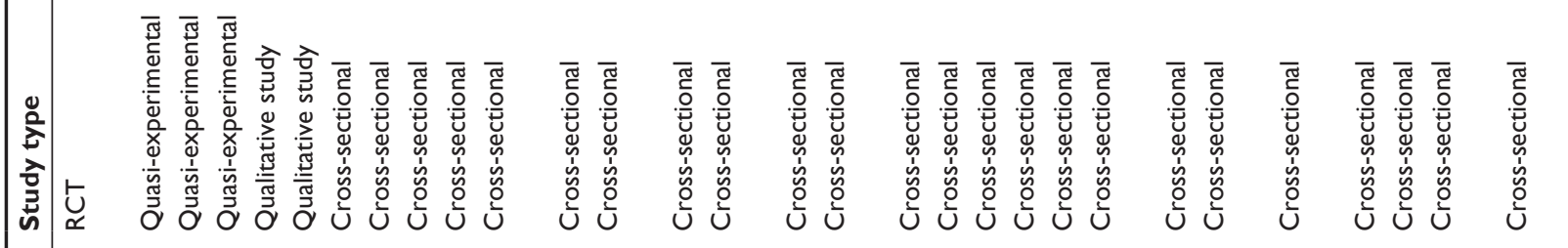
ป

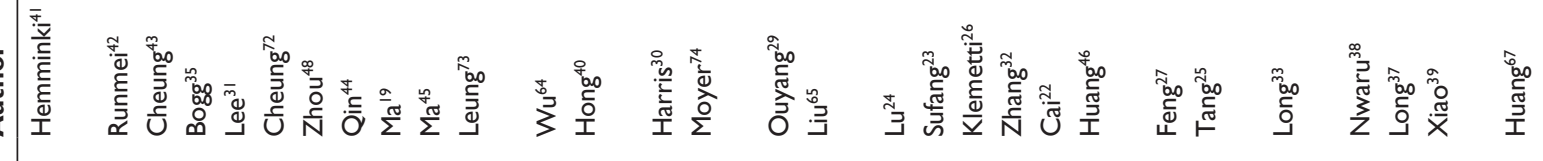
(1)
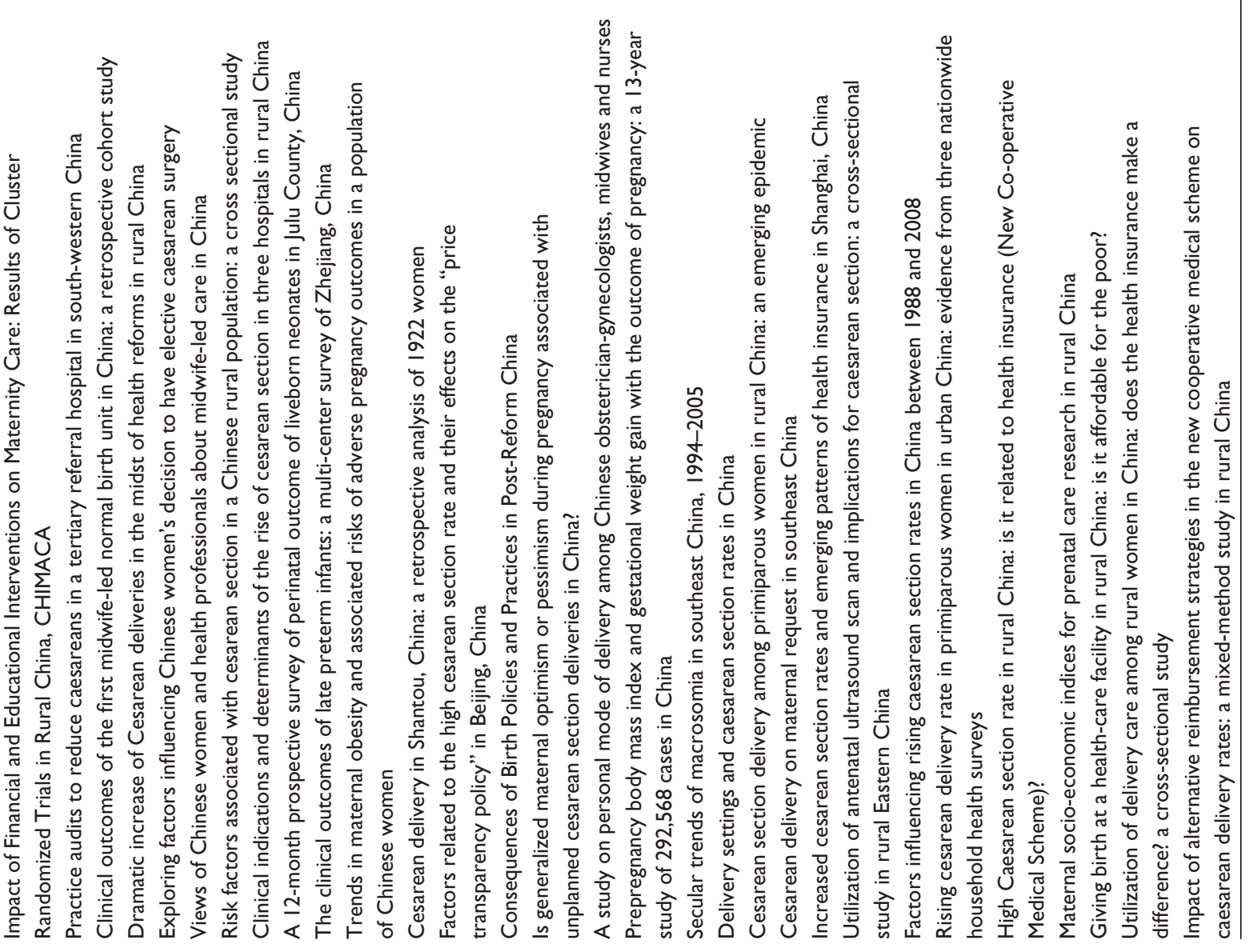


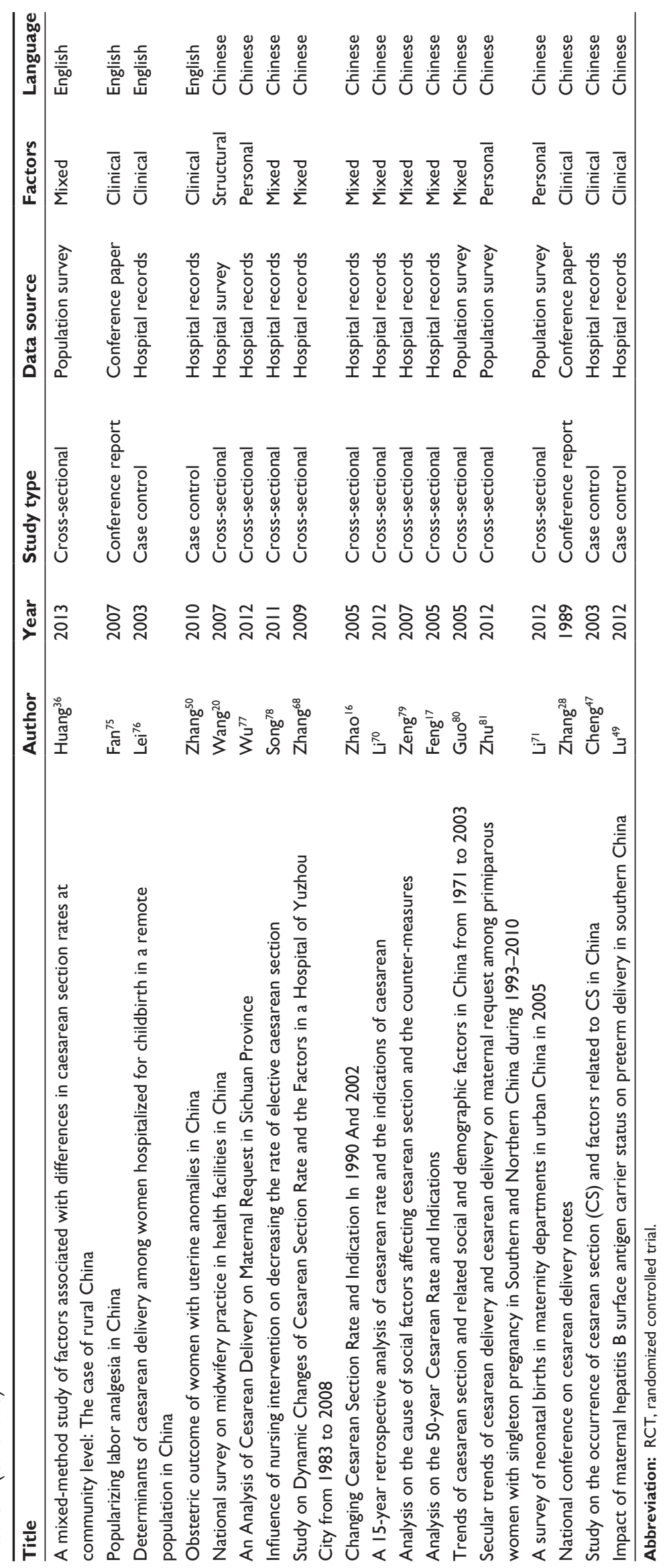


patients during labor and delivery may mask the real decisionmaking, and interpretation of CDMR from clinical records therefore warrants careful attention. Second, for the emergency classification approach, women's specific expectations and experiences of labor and delivery may introduce substantial information bias. How this affects the results is uncertain, but caution is required in the interpretation of preferences. Unfortunately, more robust classification - such as that proposed by Robson ${ }^{34}$ - to identify unnecessary cesareans has never been done, leaving a substantial literature gap.

\section{Structural factors}

There are 29 studies on structural factors fueling rising cesarean section in the People's Republic of China. Using information on cesarean sections collected from women's recollections, for the first time, the authors reported a rise of cesarean sections from $4.7 \%$ in $1960-1979$ to $22.5 \%$ in 1988-1993 at the population level. ${ }^{22}$ Using a populationbased survey, the authors analyzed the reproductive history of 1,957 married women in 1993. Information on delivery mode was collected for a 30-year period, and the association of cesareans with clinical, demographic, and socioeconomic factors was analyzed. The study reported that form of medical payment was associated with use of cesarean section. They found that women who were covered by the government insurance scheme had a 6 times higher odds of cesarean birth compared with those covered by cooperative medical insurance. Since the government insurance offered higher cost reimbursement, the authors argued that it was the distorted incentives within the insurance arrangements that contributed to the rise in cesarean births. They further suggested that the fee-for-service payment arrangement to hospitals may exaggerate the perverse incentives introduced for doctors, since doctors would have strong motivations for providing cesareans to make more money.

With similar designs as Cai et al, ${ }^{22}$ Tang et $\mathrm{al}^{25}$ analyzed factors affecting rising cesarean delivery rates in urban China. Using three national cross-sectional survey databases, the authors analyzed 3,559 primiparous women's reproductive information, representing urban China in 1993, 1998, and 2003. The authors found that rates of cesarean section tripled in urban China from 1990 to 2003, and women living in large cities had 2.4 times the odds of having a cesarean delivery compared to women living in small cities. Women's educational achievement was one of the main determinants of cesarean section in urban China, with 4.5 times higher odds of cesarean section for those who had college or higher education compared with the illiterate/primary school group.
While insurance coverage seemed to be positively associated with cesarean delivery, the role of income was not statistically significant. Tang et al attributed the association between higher level of education and cesarean birth to women's own choices. They argued that women may fear pain, or want to give birth on a specific date or at a time believed to be auspicious, they may want to protect the baby's brain, and may also be concerned for their sexual life following a vaginal delivery, and this would be more pronounced amongst those who are well-educated. The authors also discussed the distorted providers' incentives as a potential determinant of rising cesareans, however no clear evidence was provided in support of this hypothesis.

Klemetti et $\mathrm{al}^{26}$ analyzed the factors affecting rising cesarean section in rural China, using the same data sources as Tang et $\mathrm{al}^{25}$ used. However, unlike Tang et al's findings for urban China, the study found that household income was a strong predictor of cesarean section in rural China, where an odds ratio (OR) of 2.4 was found comparing the highest with the lowest quintiles. While the effect of education was less strong than in the urban settings, with an OR of 2.6, the authors reported that higher level hospitals were more likely to provide cesareans than lower level ones (OR 4.0). More interestingly, the authors found that the strongest predictor for cesarean delivery in rural China was the uptake of antenatal care, where women who had any antenatal care had 8.7 times the odds for a cesarean section compared to those who did not use such services. With this evidence, the authors argued that the increased cesarean rates cannot be explained solely by medical reasons, and there might be an overuse of unnecessary, expensive services for Chinese health providers, though the underlying mechanisms were not deliberately discussed.

Using the other national data source from the United Nations Population Fund, Sufang et $\mathrm{al}^{23}$ confirmed that higher level hospitals had higher rates of cesareans than lower level ones, but the rates in lower level hospitals were rising substantially, nearing those in the large hospitals. Based on a natural experiment design, Bogg et $\mathrm{al}^{35}$ observed rising trends of cesarean sections in five rural counties from 2001-2007 and found that revenue from cesareans made up $72 \%-85 \%$ of total delivery fee revenue. They suggested that the rapid increase in cesareans and the associated expenditures in rural China may be attributed to the introduction of the NCMS, which offers more generous cost reimbursement for cesarean delivery. The authors argued that the incentives of Chinese health providers are distorted due to the fee-forservice payment system, which has introduced distorted 
behaviors for providers, such as over-prescription of drugs and antibiotics, overuse of high-technological diagnostic tests, and a treatment pattern of expensive curative rather than basic and preventive primary care.

The concerns about whether health providers' distorted behavior affects the rise in cesareans in the People's Republic of China have generated a lively debate. Those who support such a hypothesis justify it largely on the basis that higher income households and those who have insurance coverage are more likely to have cesarean sections, since doctors can make more money from these groups. ${ }^{36-38}$ But there is also some evidence refuting this hypothesis. For example, comparing women who were covered by the NCMS and those who were not, Xiao et $\mathrm{al}^{39}$ found that there was no overuse of delivery services, including cesareans, among the women reimbursed by the NCMS. Similarly, Hong, ${ }^{40}$ separating clinically indicated and nonclinically indicated cesarean sections in 32 tertiary hospitals in Beijing, found that nonmedically indicated cesarean sections were not associated with health insurance in urban settings. Long et al, ${ }^{33}$ on the other hand, found an association between insurance and nonemergency cesarean delivery; however, only when cesarean rates were at a modest level $(13 \%-82 \%)$. The choice of such thresholds was somewhat arbitrary and since the insurance coverage for intrapartum care is already universal in the People's Republic of China, it is hard to believe that the comparison between women who are insured and those who are not insured are robust to substantial selection bias.

The most robust evidence relating cesarean sections to financial incentives is based on randomly allocated interventions in the context of a trial. Using a community-based cluster randomized controlled trial in two provinces in the People's Republic of China, Hemminki et $\mathrm{al}^{41}$ found that financial interventions covered part of women's costs for prenatal and postnatal care, but they were associated with only a moderate increase in cesarean sections (OR 1.17; 95\% confidence interval [0.96-1.43]).

Feng et $\mathrm{al}^{27}$ performed a trends analysis on the factors affecting rising cesarean sections in the People's Republic of China. Since doctors would expect higher revenue from the families with a higher ability to pay, the authors hypothesized that, if the cesarean epidemic in the People's Republic of China is fuelled by distorted financial incentives, then women who are richer and insured would have experienced a faster rise in cesarean births over recent decades. However, using data from four national cross-sectional surveys between 1988 and 2008, the authors found that although cesareans were more common among the richer, well-educated, and insured women, the rate increased alarmingly in all socioeconomic groups and had a faster rise amongst the groups with lower income, no health insurance coverage, and less educational achievement. Furthermore, this study found that the socioeconomic region of residence was a more important determinant for cesarean sections than the women's individual socioeconomic characteristics, questioning the link between women's personal preference, and cesarean births. Hence, supply side factors may be more important predictors for cesarean sections than ability to pay or education. The strong regional variation in the cesarean section rate, as found in this study, points to structural factors related to the supply of services as an important driver of the increase. As an interpretation, the authors argued that it may be due to the People's Republic of China's health development approach focusing on specialized care - that contributes to the epidemic of cesarean sections in this country. The People's Republic of China has marginalized midwifery and midwifery education was discontinued in 1993. As a result, the density of nurses and midwives is lower than in other countries with similar income levels, and the number of doctors trained in Western medicine doubled in the past 20 years. Hospitals in urban and wealthier regions are better equipped and have more qualified staff than those in more remote rural regions, making cesarean section more accessible.

The contribution of specialized obstetric care to rising cesarean sections, as proposed by Feng et $\mathrm{al}^{27}$ is supported by several intervention studies initiated from the clinical and midwifery disciplines. For example, Runmei et $\mathrm{al}^{42}$ conducted an intervention study in a tertiary referral hospital in Southwestern China. With the auditing of surgeons' practices as the key intervention, cesarean section rates in this hospital decreased by $20 \%$ per year between 2005 and 2011. Cheung et $\mathrm{al}^{43}$ organized an innovative midwife-led normal birth unit in one tertiary hospital in 2008, aiming to facilitate normal birth and enhance midwifery practice. Based on a retrospective cohort design, the authors reported a $33 \%$ reduction in the rates of cesarean section for women who used midwife-led care. As a recommendation, the authors proposed a separation of obstetric care from maternity care and a revisit of midwife care as an independent discipline. Notwithstanding these findings, midwifery and normal delivery propositions seems to be out of Chinese health policy makers' perspective and evidence on this topic is still insufficient to influence current policy making.

As a summary for nonclinical factors affecting rising cesareans in the People's Republic of China, there is a lively debate on whether women's preferences or providers' distorted 
financial incentives affected the rise in cesarean sections. Notwithstanding, recent evidence suggests that it might be the People's Republic of China's health development approach - focusing on specialized care and marginalizing primary care - that is playing a role, though further work is warranted to strengthen the causal link.

\section{Clinical factors}

There are three types of designs used to investigate pure clinical factors affecting cesarean sections in the People's Republic of China: hospital records analysis (6 studies), population surveys (2 studies), and case control studies (4 studies). By describing the proportions of various clinical indications for performing cesareans, the first type of design, hospital records analysis, generally shows that cephalopelvic disproportion, fetal distress, breech presentation, abnormal pelvis, macrosomia, dystocia, hypertension, multiple birth, premature rupture of membranes, oligohydramnios, late preterm births, and older maternal age are the most commonly reported clinical indications. ${ }^{15-17,44,45}$ However, the limitation of this type of research is obvious since only proportions of each clinical indication are described, while no relative risks would be arrived at for comparisons between factors.

To further strengthen the association of various risk factors with the use of cesarean section, some authors sampled out cases of deliveries from hospital records, completed them with some demographic factors, and did crosssectional analyses on the various clinical factors affecting the utilization of cesarean section. Using such an approach, Ma et $\mathrm{al}^{19}$ reported a positive association of multiple births, large for gestational age, pregnancy complications, and older maternal age with cesarean births. To accommodate wider factors, some authors generalized such an approach to the population level. For example, Huang et $\mathrm{a}^{46}$ investigated the association between times of antenatal ultrasound utilization and the use of cesarean section based on population surveys and found an OR of 1.36, which means that one additional antenatal ultrasound scan would increase the possibility of performing a cesarean section around 1.36 times. To strengthen the causal relationship, some authors build up this approach by using case control or nested case control designs. For example, Cheng et al ${ }^{47}$ compared 6,421 vaginal and 7,650 cesarean births in 48 hospitals from three metropolitan cities in the People's Republic of China and found that birth weight larger than 4,000 g, maternal obesity, cephalopelvic disproportion, fetal distress, dystocia, and placenta previa were the main determinants for having a cesarean section. Zhou et $\mathrm{al}^{48}$ conducted a similar analysis for a rural Chinese population and identified hypertension, breech presentation, dystocia, preterm delivery, and older age as predictors of cesarean births.

Furthermore, there are some case control studies examining whether a specific disease is association with cesarean section. Lu et al ${ }^{49}$ compared mothers who were hepatitis B surface antigen carriers with those who were not based on hospital records, and reported that such a factor is not statistically associated with cesarean procedures. Using a similar design, Zhang et $\mathrm{al}^{50}$ reported that mothers with uterine anomalies have a higher probability of cesarean birth.

\section{Consequences of cesarean sections}

Research on the consequences of cesareans are relatively rare and out of focus, and in general the evidence ranked weakly. Of the 30 articles identified, 13 studied clinical outcomes for cesarean birth, 9 studied child health outcomes, 7 studied maternal health outcomes, and only 1 studied health system level outcomes (Table 3).

In the one study addressing structural consequences, Long et $\mathrm{al}^{37}$ - using repeated cross-sectional survey data found that the expenditure for facility-based delivery greatly increased in rural China over 1998-2007 because of greater use of more cesarean deliveries. On average, the out of pocket payment for cesarean section constituted $31.8 \%$ of a poor rural household's annual income.

The 13 studies on clinical outcomes varied widely in the specific outcomes. Two studies were based on a case control design and the other eleven were cross-sectional studies. For the two case control studies, one found that cesarean sections were associated with lower cord blood plasmin activity and lower umbilical blood IgG, IgM, C3, and C4 compared to vaginal delivery. ${ }^{51}$ The second case control study, making the same comparisons, found no association between cesarean birth and intraventricular hemorrhage. ${ }^{52}$ The eleven cross-sectional studies consistently found that cesarean sections were associated with higher risks of venous thromboembolism, surgical site infection, and postpartum infection. However, evidence on whether women who had a cesarean section are more likely to have postpartum hemorrhage is contradictory between the two studies reporting such outcomes. ${ }^{53,54}$ For example, $\mathrm{Cai}^{53}$ found that performing cesareans is associated with higher risk of postpartum hemorrhage, while Jiang et al ${ }^{54}$ found no associations that were statistically significant. Cesarean births seem to have higher risks of neonatal injury as reported by Cai. ${ }^{53}$ And repeated cesareans were associated with higher hysterectomy. ${ }^{55}$ However, the associations of cesarean section with other clinical outcomes were not profound; for example, 


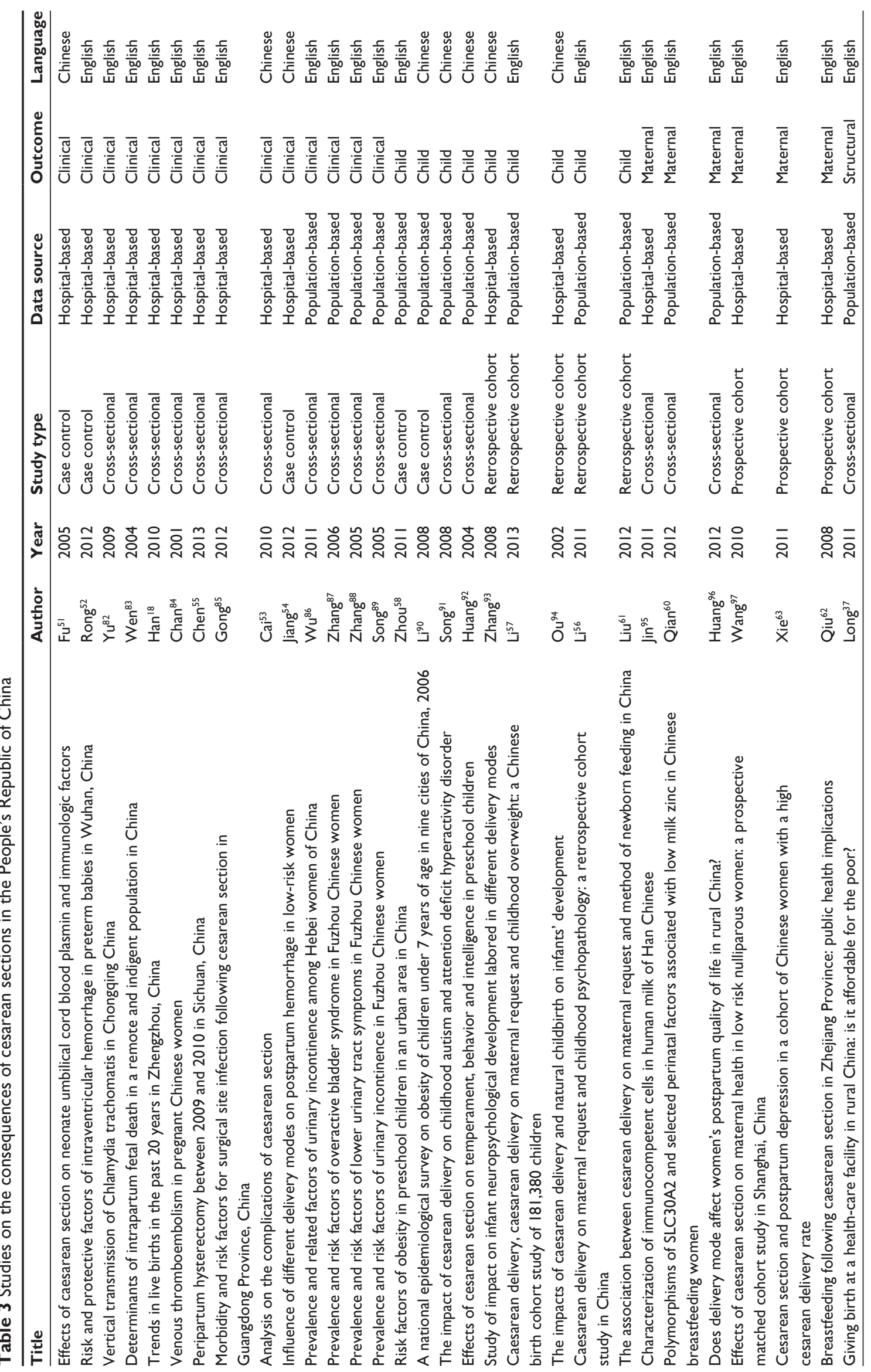


overactive bladder, lower urinary tract storage symptoms, incontinence, vertical transmission of Chlamydia trachomatis, intraventricular hemorrhage in preterm babies, intrapartum fetal death, neonatal respiratory distress syndrome, and low neonatal Apgar scores.

Studies examining the consequences of cesarean section on child health examined breastfeeding behaviors, child obesity, and physiological development. Of the 8 articles identified, only 3 were published in peer-reviewed journals, including 2 retrospective cohort studies ${ }^{56,57}$ and 1 case control design. ${ }^{58}$ In general, the findings are consistent in showing that cesarean section on maternal request is a risk factor for child obesity, which is consistent with international evidence. ${ }^{59}$ However, the link from cesareans to child physiological development is not robust.

There are 5 papers published in peer-review journals on the maternal health consequences after performing a cesarean section. One was based on cross-sectional data, where no associations of breast milk zinc concentration and self-reported postpartum health with cesarean births were found.$^{60}$ The other 4 were based on prospective cohort study designs, where one cohort reported that women performing cesarean births were less likely to provide exclusive breastfeeding and formula feeding was more likely to be offered to the infant, ${ }^{61}$ while another found a contrary result. ${ }^{62}$ Based on a 2-week follow-up of 534 women delivering babies in two hospitals, Xie et a ${ }^{63}$ found that cesarean section is associated with increased risk of postpartum depression with an adjusted relative risk near 2. Notwithstanding, the actual or perceived safety of cesarean section in the People's Republic of China is pretty rare.

\section{Conclusion}

With a national rate near $40 \%$ and a rapid rise in the country over the past decade, there is no doubt that the rising rate of cesarean sections has become a national epidemic in the People's Republic of China, warranting careful policy considerations. However, no consensus has been made on the leverage factors that drive the increase in the use of cesarean section, particularly for those nonclinical factors. While the main debate is around whether the rise in cesarean sections is fueled by women's own preferences or providers' distorted financial incentives, recent evidence suggest that it might be the more macro level structural factors that are playing a part, ie, the People's Republic of China's health development approach focusing on specialized care and marginalizing primary care, though further research is warranted to under- stand the underlying mechanisms. Compared to the lively debate analyzing the trends and factors that affect the rising number of cesarean sections, knowledge of the consequences of cesareans is quite limited in the People's Republic of China. The only robust evidence is that children of cesarean births are more likely to be obese. However, research on how the uptake of cesarean section affects women's health is underdeveloped.

\section{Author contributions}

Xing Lin Feng and Ying Wang conceived the paper, and searched and reviewed the literature. Xing Lin Feng wrote the first draft and the other authors commented and revised on the various versions. All authors contributed toward interpretation of data, drafting, and revising the manuscript.

\section{Acknowledgments}

The China Medical Board project 12-119PUHSCGNL, the Program for New Century Excellent Talents in University (NCET-12-0009) and the project 71303010 supported by the National Natural Science Foundation of China funded this study.

\section{Disclosure}

The authors report no conflicts of interest in this work.

\section{References}

1. Victora CG, Barros FC. Beware: unnecessary caesarean sections may be hazardous. Lancet. 2006;367(9525):1796-1797.

2. Villar J, Carroli G, Zavaleta N, et al; World Health Organization 2005 Global Survey on Maternal and Perinatal Health Research Group. Maternal and neonatal individual risks and benefits associated with caesarean delivery: multicentre prospective study. BMJ. 2007;335(7628):1025.

3. World Health Organization. Monitoring Emergency Obstetric Care: A Handbook. Geneva, Switzerland: World Health Organization; 2009.

4. Ronsmans C, Holtz S, Stanton C. Socioeconomic differentials in caesarean rates in developing countries: a retrospective analysis. Lancet. 2006;368(9546):1516-1523

5. Cavallaro FL, Cresswell JA, França GV, Victora CG, Barros AJ, Ronsmans C. Trends in caesarean delivery by country and wealth quintile: cross-sectional surveys in southern Asia and sub-Saharan Africa. Bulletin of the World Health Organization. Epub August 9, 2013.

6. No authors listed. Appropriate technology for birth. Lancet. 1985;2(8452): 436-437.

7. Althabe F, Sosa C, Belizán JM, Gibbons L, Jacquerioz F, Bergel E. Cesarean section rates and maternal and neonatal mortality in low-, medium-, and high-income countries: an ecological study. Birth. 2006;33(4):270-277.

8. Betrán AP, Merialdi M, Lauer JA, et al. Rates of caesarean section: analysis of global, regional and national estimates. Paediatr Perinat Epidemiol. 2007;21(2):98-113.

9. Mazzoni A, Althabe F, Liu NH, et al. Women's preference for caesarean section: a systematic review and meta-analysis of observational studies. BJOG. 2011;118(4):391-399.

10. Feng XL, Guo S, Hipgrave D, et al. China's facility-based birth strategy and neonatal mortality: a population-based epidemiological study Lancet. 2011;378(9801):1493-1500. 
11. Feng XL, Zhu J, Zhang L, et al. Socio-economic disparities in maternal mortality in China between 1996 and 2006. BJOG. 2010;117(12): $1527-1536$.

12. Feng XL, Shi G, Wang Y, et al. An impact evaluation of the Safe Motherhood Program in China. Health Econ. 2010;19 Suppl:69-94.

13. Feng XL, Xu L, Guo Y, Ronsmans C. Socioeconomic inequalities in hospital births in China between 1988 and 2008. Bull World Health Organ. 2011;89(6):432-441.

14. Lumbiganon P, Laopaiboon M, Gülmezoglu AM, et al; World Health Organization Global Survey on Maternal and Perinatal Health Research Group. Method of delivery and pregnancy outcomes in Asia: the WHO global survey on maternal and perinatal health 2007-2008. Lancet. 2010;375(9713):490-499.

15. Zheng $P$, Huang $X H$, Wang $S$. [The changing trend of cesearean section rates in 35 years]. Zhonghua Fu Chan Ke Za Zhi. 1996;31(3):142-145. Chinese.

16. Zhao LP, Shen JF, Xu HO. Changing cesarean section rate and indication in 1990 and 2002. Maternal and Child Health Care of China. 2005;20:1341-1342.

17. Feng L, Yue J. Analysis on the 50-year cesarean rate and indications. Journal of Huazhong University of Science and Technology (Health Sciences). 2005;34:628-630.

18. Han W, Song J, Liu A, et al. Trends in live births in the past 20 years in Zhengzhou, China. Acta Obstet Gynecol Scand. 2011;90(4):332-337.

19. Ma L, Liu CQ, Zheng XL, et al. A 12-month prospective survey of perinatal outcome of liveborn neonates in Julu County, China. Chin Med J (Engl). 2010;123(20):2781-2785.

20. Wang B, Shi Q, Wang Y, Li N, Shi L. [National survey on midwifery practice in health facilities in China]. Zhonghua Fu Chan Ke Za Zhi. 2007;42(5):305-308. Chinese.

21. Torloni MR, Betran AP, Souza JP, et al. Classifications for cesarean section: a systematic review. PLoS One. 2011;6(1):e14566.

22. Cai WW, Marks JS, Chen CH, Zhuang YX, Morris L, Harris JR. Increased cesarean section rates and emerging patterns of health insurance in Shanghai, China. Am J Public Health. 1998;88(5):777-780.

23. Sufang G, Padmadas SS, Fengmin Z, Brown JJ, Stones RW. Delivery settings and caesarean section rates in China. Bull World Health Organ. 2007;85(10):755-762

24. Lu Y, Zhang J, Lu X, Xi W, Li Z. Secular trends of macrosomia in southeast China, 1994-2005. BMC Public Health. 2011;11:818.

25. Tang $\mathrm{S}, \mathrm{Li} \mathrm{X}, \mathrm{Wu} \mathrm{Z}$. Rising cesarean delivery rate in primiparous women in urban China: evidence from three nationwide household health surveys. Am J Obstet Gynecol. 2006;195(6):1527-1532.

26. Klemetti R, Che X, Gao Y, et al. Cesarean section delivery among primiparous women in rural China: an emerging epidemic. Am JObstet Gynecol. 2010;202(1):65. e1-e65. e6.

27. Feng XL, Xu L, Guo Y, Ronsmans C. Factors influencing rising caesarean section rates in China between 1988 and 2008. Bull World Health Organ. 2012;90(1):30-39, 39A.

28. Zhang ZJ, Liu DL. National conference on cesarean delivery notes. Journal of Practical Obstetrics and Gynecology. 1989;5:272-277.

29. Ouyang YQ, Zhang Q. A study on personal mode of delivery among Chinese obstetrician-gynecologists, midwives and nurses. Arch Gynecol Obstet. 2013;287(1):37-41.

30. Harris A, Gao Y, Barclay L, et al. Consequences of birth policies and practices in post-reform China. Reprod Health Matters. 2007;15(30): 114-124.

31. Lee LY, Holroyd E, Ng CY. Exploring factors influencing Chinese women's decision to have elective caesarean surgery. Midwifery. 2001;17(4):314-322.

32. Zhang J, Liu Y, Meikle S, Zheng J, Sun W, Li Z. Cesarean delivery on maternal request in southeast China. Obstet Gynecol. 2008;111(5): $1077-1082$

33. Long Q, Klemetti R, Wang Y, Tao F, Yan H, Hemminki E. High Caesarean section rate in rural China: is it related to health insurance (New Co-operative Medical Scheme)? Soc Sci Med. 2012;75(4): $733-737$.
34. Robson MS. Can we reduce the caesarean section rate? Best Pract Res Clin Obstet Gynaecol. 2001;15(1):179-194.

35. Bogg L, Huang K, Long Q, Shen Y, Hemminki E. Dramatic increase of Cesarean deliveries in the midst of health reforms in rural China. Soc Sci Med. 2010;70(10):1544-1549.

36. Huang K, Tao F, Faragher B, et al. A mixed-method study of factors associated with differences in caesarean section rates at community level: the case of rural China. Midwifery. 2013;29(8):911-920.

37. Long Q, Zhang Y, Raven J, et al. Giving birth at a health-care facility in rural China: is it affordable for the poor? Bull World Health Organ. 2011;89(2):144-152.

38. Nwaru BI, Klemetti R, Kun H, et al. Maternal socio-economic indices for prenatal care research in rural China. Eur J Public Health. 2012;22(6):776-781.

39. Xiao S, Yan H, Shen Y, et al. Utilization of delivery care among rural women in China: does the health insurance make a difference? a crosssectional study. BMC Public Health. 2010;10:695.

40. Hong X. Factors related to the high cesarean section rate and their effects on the "price transparency policy" in Beijing, China. Tohoku J Exp Med. 2007;212(3):283-298.

41. Hemminki E, Long Q, Zhang WH, et al. Impact of financial and educational interventions on maternity care: results of cluster randomized trials in rural China, CHIMACA. Matern Child Health J. 2013;17(2): 208-221.

42. Runmei M, Terence TL, Yonghu S, et al. Practice audits to reduce caesareans in a tertiary referral hospital in south-western China. Bull World Health Organ. 2012;90(7):488-494.

43. Cheung NF, Mander R, Wang X, Fu W, Zhou H, Zhang L. Clinical outcomes of the first midwife-led normal birth unit in China: a retrospective cohort study. Midwifery. 2011;27(5):582-587.

44. Qin C, Zhou M, Callaghan WM, et al. Clinical indications and determinants of the rise of cesarean section in three hospitals in rural China. Matern Child Health J. 2012;16(7):1484-1490.

45. Ma X, Huang C, Lou S, et al; Provincial Collaborative Study Group for Late-Preterm Infants. The clinical outcomes of late preterm infants: a multi-center survey of Zhejiang, China. J Perinat Med. 2009;37(6): 695-699.

46. Huang K, Tao F, Raven J, Liu L, Wu X, Tang S. Utilization of antenatal ultrasound scan and implications for caesarean section: a crosssectional study in rural Eastern China. BMC Health Serv Res. 2012; 12:93.

47. Cheng YM, Yuan W, Cai WD, et al. Study on the occurrence of cesarean section (CS) and factors related to CS in China. Zhonghua Liu Xing Bing Xue Za Zhi. 2003;24(10):893-896.

48. Zhou Y, Ji N, Pang C, He D, Hou L, Cheng Y. Risk factors associated with cesarean section in a Chinese rural population: a cross sectional study. J Reprod Med. 2012;57(9-10):441-445.

49. Lu Y, Chen Y, Xiao X, et al. [Impact of maternal hepatitis B surface antigen carrier status on preterm delivery in southern China]. Nan Fang Yi Ke Da Хие Хие Bao. 2012;32(9):1369-1372. Chinese.

50. Zhang Y, Zhao YY, Qiao J. Obstetric outcome of women with uterine anomalies in China. Chin Med J (Engl). 2010;123(4):418-422.

51. Fu LJ, Zhang HD, Chen HC. Effects of caesarean section on neonate umbilical cord blood plasmin and immunologic factors. Chinese Journal of Practical Gynecology and Obstetrics. 2005;21:611-613.

52. Rong Z, Liu H, Xia S, Chang L. Risk and protective factors of intraventricular hemorrhage in preterm babies in Wuhan, China. Childs Nerv Syst. 2012;28(12):2077-2084.

53. Cai JQ. Analysis on the complications of caesarean section. Journal of Baotou Medical College. 2010;26:30-31.

54. Jiang F, Gao J, Zhou X, Liu J, Yang J, Bian X. Influence of Different Delivery Modes on Postpartum Hemorrhage in Low-risk Women. Medical Journal of Peking Union Medical College Hospital. 2012;3: 109-112.

55. Chen M, Zhang L, Wei Q, Fu X, Gao Q, Liu X. Peripartum hysterectomy between 2009 and 2010 in Sichuan, China. Int J Gynaecol Obstet. 2013;120(2):183-186. 
56. Li HT, Ye R, Achenbach TM, et al. Caesarean delivery on maternal request and childhood psychopathology: a retrospective cohort study in China. BJOG. 2011;118(1):42-48.

57. Li H, Ye R, Pei L, Ren A, Zheng X, Liu J. Caesarean delivery, caesarean delivery on maternal request and childhood overweight: a Chinese birth cohort study of 181,380 children. Pediatr Obes. 2013.

58. Zhou L, He G, Zhang J, Xie R, Walker M, Wen SW. Risk factors of obesity in preschool children in an urban area in China. Eur J Pediatr. 2011;170(11):1401-1406.

59. Huh SY, Rifas-Shiman SL, Zera CA, et al. Delivery by caesarean section and risk of obesity in preschool age children: a prospective cohort study. Arch Dis Child. 2012;97(7):610-616.

60. Qian L, Wang B, Tang N, Zhang W, Cai W. Polymorphisms of SLC30A2 and selected perinatal factors associated with low milk zinc in Chinese breastfeeding women. Early Hum Dev. 2012;88(8):663-668.

61. Liu X, Zhang J, Liu Y, Li Y, Li Z. The association between cesarean delivery on maternal request and method of newborn feeding in China. PLoS One. 2012;7(5):e37336.

62. Qiu L, Binns C, Zhao Y, Lee A, Xie X. Breastfeeding following caesarean section in Zhejiang Province: public health implications. Asia Pac J Public Health. 2008;20 Suppl:220-227.

63. Xie RH, Lei J, Wang S, Xie H, Walker M, Wen SW. Cesarean section and postpartum depression in a cohort of Chinese women with a high cesarean delivery rate. J Womens Health (Larchmt). 2011;20(12): 1881-1886.

64. Wu WL. Cesarean delivery in Shantou, China: a retrospective analysis of 1922 women. Birth. 2000;27:86-90.

65. Liu Y, Dai W, Dai X, Li Z. Prepregnancy body mass index and gestational weight gain with the outcome of pregnancy: a 13-year study of 292,568 cases in China. Arch Gynecol Obstet. 2012;286:905-911.

66. Meng Q, Xu L, Zhang Y, et al. Trends in access to health services and financial protection in China between 2003 and 2011: a cross-sectional study. Lancet. 2012;379:805-814.

67. Huang K, Tao F, Bogg L, Tang S. Impact of alternative reimbursement strategies in the new cooperative medical scheme on caesarean delivery rates: a mixed-method study in rural China. BMC Health Serv Res. 2012;12:217.

68. Zhang XL, Hua XY, Hao SX, He XH, Fei N, Chen AJ. Study on Dynamic Changes of Cesarean Section Rate and the Factors in a Hospital of Yuzhou City from 1983 to 2008. Medicine and Society. 2009; 22:35-36.

69. Wei XJ, Li RP. The Relationship of the caesarean rate with the maternal age and the infant birth weight from 1997 to 2006. Maternal and Child Health Care of China. 2010;25:26-28

70. Li XY, Wang RR. A 15-year retrospective analysis of caesarean rate and the indications of caesarean. Jilin Medical Journal 2012;33: 3674-3676.

71. Li J, Wang QH, Wu HM, et al. Zhongguo Dang Dai ErKeZaZhi [A survey of neonatal births in maternity departments in urban China in 2005]. 2012;14:7-10.

72. Cheung NF, Mander R, Wang X, Fu W, Zhou H, Zhang L. Views of Chinese women and health professionals about midwife-led care in China. Midwifery. 2011;27:842-847.

73. Leung TY, Leung TN, Sahota DS, et al. Trends in maternal obesity and associated risks of adverse pregnancy outcomes in a population of Chinese women. BJOG. 2008;115:1529-1537.

74. Moyer CA, Elsayed Y, Zhu Y, Wei Y, Engmann CM, Yang H. Is generalized maternal optimism or pessimism during pregnancy associated with unplanned cesarean section deliveries in China? J Pregnancy. 2010;754938.

75. Fan ZT, Gao XL, Yang HX. Popularizing labor analgesia in China. Int J Gynaecol Obstet. 2007;98:205-207.

76. Lei H, Wen SW, Walker M. Determinants of caesarean delivery among women hospitalized for childbirth in a remote population in China. J Obstet Gynaecol Can. 2003;25:937-943.
77. Wu FY, Zhang Y, Xiao B, Xiong Q. An Analysis of Cesarean Delivery on Maternal Request in Sichuan Province. Journal of Practical Obstetrics and Gynecology. 2012;28:187-190.

78. Song H. Influence of nursing intervention on decreasing the rate of elective caesarean section. Chinese Nursing Research 2011;25:2215.

79. Zeng GQ, Huang ZY, Gao JX. Analysis on the cause of social factors affecting cesarean section and the counter-measures. Maternal and Child Health Care of China. 2007;22:418-420.

80. Guo XF, Zhao FM, Wu KS, et al. Trends of caesarean section and related social and demographic factors in China from 1971 to 2003. Chinese Journal of Perinatal Medicine. 2005;8:145-149.

81. Zhu YB, Li HT, Zhang YL, Li ZW, Zhang L, Liu JM. [Secular trends of cesarean delivery and cesarean delivery on maternal request among primiparous women with singleton pregnancy in Southern and Northern China during 1993-2010]. Zhonghua Yi XueZaZhi. 2012; 92:1734-1737.

82. Yu J, Wu S, Li F, Hu L. Vertical transmission of Chlamydia trachomatis in Chongqing China. Curr Microbiol. 2009;58:315-320.

83. Wen SW, Lei H, Kramer MS, Sauve R. Determinants of intrapartum fetal death in a remote and indigent population in China. J Perinatol. 2004;24:77-81.

84. Chan LY, Tam WH, Lau TK. Venous thromboembolism in pregnant Chinese women. Obstet Gynecol. 2001;98:471-475.

85. Gong SP, Guo HX, Zhou HZ, Chen L, YuYH. Morbidity and risk factors for surgical site infection following cesarean section in Guangdong Province, China. J Obstet Gynaecol Res. 2012;38:509-515.

86. Wu XH, Liu XX, Xie KH, Wang RM, Wu YX, Liu YG. Prevalence and related factors of urinary incontinence among Hebei women of China. Gynecol Obstet Invest. 2011;71:262-267.

87. Zhang W, Song Y, He X, Huang H, Xu B, Song J. Prevalence and risk factors of overactive bladder syndrome in Fuzhou Chinese women. Neurourol Urodyn. 2006;25:717-721.

88. Zhang W, Song Y, He X, et al. Prevalence and risk factors of lower urinary tract symptoms in Fuzhou Chinese women. Eur Urol. 2005;48:309-313.

89. Song YF, Zhang WJ, Song J, Xu B. Prevalence and risk factors of urinary incontinence in Fuzhou Chinese women. Chin Med J (Engl). 2005;118:87-92.

90. Li H. [A national epidemiological survey on obesity of children under 7 years of age in nine cities of China, 2006]. ZhonghuaErKeZaZhi. 2008;46:174-178.

91. Song HM, Zhu LM, Wang BB, Lin R. The impact of cesarean delivery on childhood autism and attention deficit hyperactivity disorder. Journal of Jining Medical College. 2008;31:63-65.

92. Huang X, Wang ML, Jing J, et al. Effects of cesarean section on temperament, behavior and intelligence in preschool children. Chinese Journal of Child Health Care. 2004;12:103-105.

93. Zhang WK, Hao B, Zhao GL, et al. Study of impact on infant neuropsychological development labored in different delivery modes. Chinese Journal of Child Health Care. 2008;16:141-143.

94. Ou P, Hong SQ, Wei AL, Qian QF, Ouyang Y. The impacts of caesarean delivery and natural childbirth on infants' development. Strait Journal of Preventive Medicine. 2002;8:75-76.

95. Jin YY, Wei Z, Cao RM, Xi W, Wu SM, Chen TX. Characterization of immunocompetent cells in human milk of Han Chinese. J Hum Lact. 2011;27:155-162.

96. Huang K, Tao F, Liu L, Wu X. Does delivery mode affect women's postpartum quality of life in rural China? J Clin Nurs. 2012;21: 1534-1543.

97. Wang BS, Zhou LF, Coulter D, et al. Effects of caesarean section on maternal health in low risk nulliparous women: a prospective matched cohort study in Shanghai, China. BMC Pregnancy Childbirth. 2010;10:78. 
International Journal of Women's Health

Dovepress

\section{Publish your work in this journal}

The International Journal of Women's Health is an international, peer- a very quick and fair peer-review system, which is all easy to use. reviewed open-access journal publishing original research, reports, editorials, reviews and commentaries on all aspects of women's healthcare including gynecology, obstetrics, and breast cancer. The Visit http://www.dovepress.com/testimonials.php to read real quotes from published authors.

manuscript management system is completely online and includes

Submit your manuscript here: http://www.dovepress.com/international-journal-of-womens-health-journal 